\title{
Perfil dos Acidentes Rurais em Agências do INSS de São Paulo no ano 2000
}

Ila Maria Corrêa'

Rosa Yasuko Yamashita ${ }^{2}$

Hamilton Humberto Ramos ${ }^{3}$

André Vinícius Favrim Franco 4

\section{Agricultural Accidents Diagnosis in Public Health (System) Agencies in São Paulo - year 2000}

'Engenheira Agrícola, Dra. Pesquisadora do Centro APTA de Engenharia e Automoção do Instituto Agronômo/SAA

2Engenheira Agrônoma., MS . Pesquisadora da FUNDACENTRO/ Ministério do Trabalho e Emprego ${ }^{3}$ Engenheiro Agrônomo, Dr., Pesquisador do Centro APTA de Engenharia e Automoção do Instituto Agronômico

Técnico em Informática, Bolsista da FAPESP

Agradecimento

Os autores agradecem às Agências do INSS localizadas nos municípios de Araraquara, Assis, Bragança Paulista, Itapetininga, Itapeva, Jaboticabal, Marilia, Orlândia, Ourinhos e Votuporanga, bem como às suas Gerências Executivas, a permissão para consulta de seus arquivos.
Levantamento realizado com o objetivo de caracterizar os acidentes rurais registrados em agências da previdência social. Foram amostradas dez agências no estado de São Paulo tomando-se como base o ano de 2000. Os acidentes foram avaliados em termos da distribuição percentual das seguintes características: perfil do acidentado (sexo, idade, estado civil), tarefa em execução na ocasião do acidente, natureza da causa do acidente, tipo de agente da lesão, partes do corpo atingidas, tipos de lesões e conseqüência do acidente (dias de afastamento, ocorrência de internação). Um total de 949 registros de acidentes foram identificados. Dos inúmeros relatos de acidentes apresentados observou-se que: a grande maioria deles está relacionada à colheita manual de produtos agrícolas $(41,7 \%)$ sendo as ferramentas manuais a natureza predominante das causas $(34,3 \%)$ e os ferimentos/contusões o tipo de lesão mais comum (68,9\%). O principal agente da lesão foram as batidas contra objetos ou partes mecânicas $(43,8 \%$ ) sendo os membros superiores os mais atingidos $(43,2 \%)$.

Palavras-chaves Acidentes Rurais, Estatísticas de Acidentes.

It was made a sampling with the aim to study the agricultural accidents in Public Health agencies. Ten agencies were consulted in São Paulo state on the year 2000. The accidents were evaluated by the percentual distribution of follows data: characteristics of victim in an accident (sex, age, marital status); activity executed when occurred the accident; nature of cause; agent of injury; affected body members; kinds of lesions and result of accident (resting) days, overnights in hospital). It was identified 949 records of accidents and had been observed that the major was related to manual picking $(41,7 \%)$ which manual tools were the principal accidents causes $(34,3 \%)$ and the most injuries were trauma/notch $(68,9 \%)$. The main agent of injury was hit against mechanical parts or objects $(43,8 \%)$ and the higher limbs of the body were the most affected (43,2\%).

Keywords Agricultural Accidents, Statistics of Accidents. 


\section{Introdução}

Em BRASIL (2003a) e BRASIL (2003b) se verifica a preocupação do governo federal em manter uma base de dados para gerar indicadores estatísticos que permitam avaliar o custo social dos acidentes de trabalho e subsidiar estudos e formulação de políticas públicas de prevenção de acidentes, mas, as estatísticas geradas ainda são muito restritas. O que é possível de obter no Anuário Estatístico da Previdência Social (BRASIL, 2003b) refere-se a registros de acidentes por atividade econômica, ao tipo de lesão, conseqüência do acidente em termos de afastamentos e incapacidade.

Historicamente, no âmbito nacional, o percentual de acidentes relacionados ao grupo da atividade agrícola, pecuária e silvicultura varia de 6 a $8 \%$ do total registrado no Instituto Nacional de Segurança e Saúde INSS, a atividade agrícola é bastante diversificada e cada uma das tarefas que a compõe tem particularidades potenciais de risco de acidentes. Seria ideal que, periodicamente, tais atividades fossem observadas, sob o aspecto da segurança e saúde do trabalhador rural e, conhecidas estatísticas de acidentes para direcionar ações de correção, conscientização, treinamento e de procedimentos na execução da tarefa.

Por falta de informações oficiais mais específicas é que algumas das estatísticas conhecidas são realizadas de maneira não sistemática, em âmbito regional, como se vê em RODRIGUES \& SILVA (1986), FUNDACENTRO (1988), SILVA \& FURLANI NETO (1999) e SCHLOSSER et al. (2000). Assim, motivado pela escassez de relatos e estatísticas sobre acidentes no meio rural, foi realizado o presente trabalho, com o objetivo de caracterizar os acidentes rurais registrados em agências da previdência social.

\section{Procedimento de amostragem}

A identificação dos acidentes rurais foi obtida junto a dez agências do Instituto Nacional de Saúde e Segurança - INSS no Estado de São Paulo, mediante formulário específico. O levantamento foi realizado no período de fevereiro de 2001 a janeiro de 2002.
Previa-se um número maior de agências amostradas, porém, a greve dos servidores da Previdência Social durante mais de três meses, prejudicou o levantamento, pois não eram permitidas consultas. Além disso, algumas das agências abordadas não deram retorno ao pedido de autorização efetuado, apesar das inúmeras mensagens de fax enviadas, informando o objetivo do trabalho e discriminando as informações a serem coletadas. A estratégia era obter a autorização da Gerência Executiva da região selecionada e depois abordar as agências do INSS a ela subordinadas. Em alguns casos se obteve a autorização da Gerência, mas não se conseguiu a consulta na agência ou, pela greve, ou por falta de retorno, ou pela agência estar passando por reforma e os arquivos estarem sem condições de acesso, ou ainda, porque no setor de cadastro não havia vigilância e não era permitido o trânsito de pessoas estranhas nesta situação.

Por outro lado, obteve-se ótima cooperação de alguns chefes de agências, que até permitiram à equipe de coleta permanecer após o horário normal de funcionamento da Agência.

O formulário utilizado para extrair as informações contidas nas Comunicações de Acidentes do Trabalho - CAT do INSS, foi baseado no questionário elaborado pela FUNDACENTRO (1988), no qual foi feito o agrupamento de alguns itens para torná-lo mais simples (ver Anexo).

Nas agências do INSS as CATs são arquivadas (em gavetas ou em volumes amarrados com barbante) misturadas a outros documentos, referentes à licença-maternidade, aposentadorias e demais benefícios. Devido ao elevado número de documentos (da ordem de milhares), para manusear de forma a identificar e separar as CATs rurais das urbanas, foi preciso restringir a amostragem ao ano 2000.

Para o entendimento dos critérios utilizados nesse trabalho cabe esclarecer que a causa e/ou agente causador do acidente nem sempre está muito bem definida na Comunicação. A adoção da informação conforme consta no campo específico do formulário do INSS para "agente causador" dá, muitas vezes, uma vaga idéia do que realmente ocorreu. Optou-se em substituir "agente causador" por "agente da lesão". Exemplo disso é encontrar como agente causador o registro 
"queda". Poderia ser queda da pessoa, ou queda de um objeto. Somente a leitura da descrição do acidente (que é sucinta) permite definir. Outro exemplo, na descrição de um acidente consta que a vítima "estava carpindo capim colonião quando torceu seu ombro esquerdo". No registro do INSS o agente causador foi o "capim colonião" mas julgase que a lesão sofrida (torção) foi causada provavelmente por movimento brusco ou esforço repetitivo.

Muitos fatores poderiam ser considerados como causas: falta de atenção, equipamento defeituoso, equipamento sem proteção, atitudes inseguras, entre outras. Para a análise dos acidentes do INSS evitou-se classificá-los em termos de "causa". Preferiu-se relacionálos ao que se chamou de "natureza da causa" e "agente da lesão". A distinção entre natureza da causa do acidente e agente da lesão é controvertida, pois tem muito de sobreposição e de subjetividade. Adotou-se, então, a classificação usada pela FUNDACENTRO (1988), com algumas modificações. O que lá se chamava "causa dos acidentes" aqui passou a ser "natureza da causa do acidente", e reduziu-se a quantida- de dos itens discriminatórios para os seguintes: mecânicas; - ferramentas manuais; - eletricidade; - agrotóxicos; - animais peçonhentos; - acidentes de trajeto; - corte de árvores/galhos; - trato com animais; outras; - fogo; - produtos químicos. E para agente da lesão, que em ARGENTINA (2000) se entende como "forma de ocorrência do acidente" classificada em quase trinta itens, aqui se adotou a seguinte classificação: queda de pessoas a altura (escada, carreta, etc); - queda de objetos; - choque contra objetos (ou partes de máquinas); - movimento falso ou brusco; - contato com eletricidade; - excesso de esforço; - contato com fogo; - exposição ao frio ou calor; - exposição a produto químico; - picada ou mordedura por animais; - atropelamento; - outras.

\section{Resultados}

\section{Características dos acidentes}

Nas dez agências consultadas foram identificados 949 registros de acidentes na área rural, referente ao ano 2000, distribuídos conforme quadro 1 .

Quadro 1 Número de registros de acidentes rurais notificados em dez agências INSS - SP, no ano 2000.

\begin{tabular}{|cccc|}
\hline $\begin{array}{c}\text { Agência } \\
\text { INSS amostrada }\end{array}$ & $\begin{array}{c}\text { Número de } \\
\text { registros }\end{array}$ & $\begin{array}{c}\text { Agência } \\
\text { INSS amostrada }\end{array}$ & $\begin{array}{c}\text { Número de } \\
\text { registros }\end{array}$ \\
\hline Araraquara (ARAQ) & 182 & Jaboticabal (JABOT) & 151 \\
Assis (ASSIS) & 68 & Marília (MARIL) & 42 \\
$\begin{array}{c}\text { Bragança Paulista } \\
\text { (BRAG) }\end{array}$ & 51 & Orlândia (ORLAN) & 82 \\
Itapetininga (ITAPT) & 80 & Ourinhos (OURIN) & 193 \\
Itapeva (ITAPV) & 67 & Votuporanga (VOTUP) & 33 \\
\hline
\end{tabular}


O perfil das pessoas acidentadas, em ter-

ta no quadro 2 e figura 1.

mos de sexo, estado civil e faixa etária cons-

Quadro 2 Perfil dos acidentados rurais. Resultado obtido em cada uma das agências INSS - SP amostradas, ano 2000.

\begin{tabular}{|c|c|c|c|c|c|c|c|c|c|c|}
\hline \multirow{2}{*}{$\begin{array}{c}\text { Item } \\
\text { verificado }\end{array}$} & \multicolumn{10}{|c|}{ Agências INSS - SP } \\
\hline & ARAQ & ASSIS & BRAG & ITAPT & ITAPV & JABOT & MARIL & ORLAN & OURIN & VOTUP \\
\hline & & & & & & $\%$ & & & & \\
\hline \multicolumn{11}{|l|}{ a) Sexo } \\
\hline Masculino & 80,2 & 80,9 & 98,0 & 86,3 & 94,0 & 88,7 & 85,7 & 96,3 & 87,6 & 97,0 \\
\hline Feminino & 19,8 & 17,6 & 2,0 & 13,7 & 4,5 & 7,3 & 14,3 & 3,7 & 12,4 & 3,0 \\
\hline Sem registro* & - & 1,5 & - & - & 1,5 & 4,0 & - & - & - & - \\
\hline \multicolumn{11}{|l|}{ b) Estado Civil } \\
\hline Casado & 57,1 & 39,7 & 45,1 & 53,8 & 62,7 & 45,7 & 57,1 & 40,2 & 51,3 & 66,7 \\
\hline Solteiro & 34,6 & 42,6 & 39,2 & 30,0 & 31,3 & 25,8 & 33,3 & 47,6 & 33,2 & 30,3 \\
\hline Viúvo/separado & 3,3 & 2,9 & 5,9 & 2,5 & - & 2,7 & 4,8 & - & 3,1 & - \\
\hline Outro & 4,9 & 14,7 & 9,8 & 13,7 & - & 23,8 & 4,8 & 12,2 & 11,9 & 3,0 \\
\hline Sem registro* & - & - & - & - & 6,0 & 2,0 & - & - & 0,5 & - \\
\hline \multicolumn{11}{|l|}{ c) Faixa etária } \\
\hline 16 a 24 anos & 15,4 & 29,4 & 21,6 & 21,3 & 19,4 & 31,1 & 19,0 & 35,4 & 34,2 & 18,2 \\
\hline 25 a 34 anos & 40,0 & 25,0 & 25,5 & 26,2 & 20,9 & 28,5 & 38,1 & 34,1 & 25,9 & 27,3 \\
\hline 35 a 44 anos & 26,9 & 27,9 & 33,3 & 22,5 & 32,8 & 22,5 & 28,6 & 22,0 & 22,3 & 36,4 \\
\hline 45 a 54 anos & 12,6 & 11,8 & 9,8 & 11,3 & 17,9 & 11,9 & 9,5 & 4,9 & 8,8 & 15,1 \\
\hline$>54$ anos & 4,9 & 2,9 & 9,8 & 10,0 & 6,0 & 6,0 & 2,4 & 1,2 & 6,7 & 3,0 \\
\hline Sem registro* & - & 2,9 & - & 8,7 & 3,0 & - & 2,4 & 2,4 & 2,1 & - \\
\hline
\end{tabular}

* Informação ausente no formulário compilado.

Nos acidentes registrados nas agências INSS-SP a operação de colheita (ver quadro 3 e figura 2) é a tarefa que apresenta, no geral, o maior índice de acidentes $(41,7 \%)$ o que já havia sido relatado por ROBIN \& YAMASHITA (1988) e é confirmado no Anuário Estatístico da Previdência Social (BRASIL, 2003b).
As ocorrências relacionadas à colheita não se referem ao uso de máquinas, pois nos casos registrados a colheita era manual, principalmente cana-de-açúcar, laranja e café. Nos registros encontrados são típicas da coTheita manual, as quedas de escada (laranja, café) e ferimentos com ferramentas manuais e com a ponta ou folha de cana. 


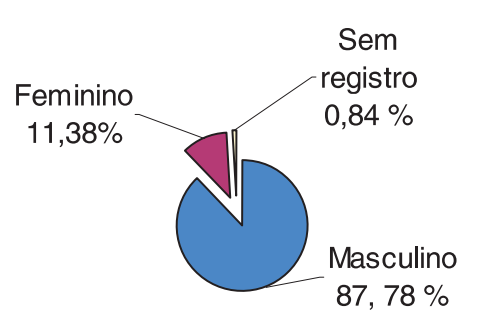

a) Sexo

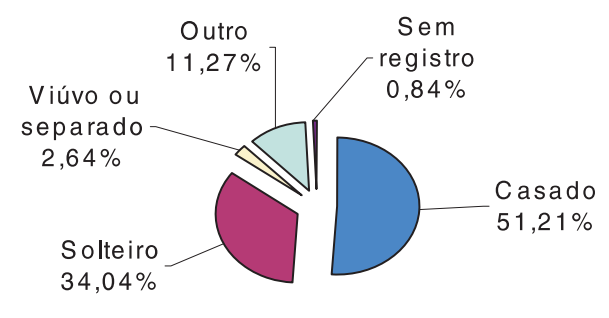

b) Estado civil

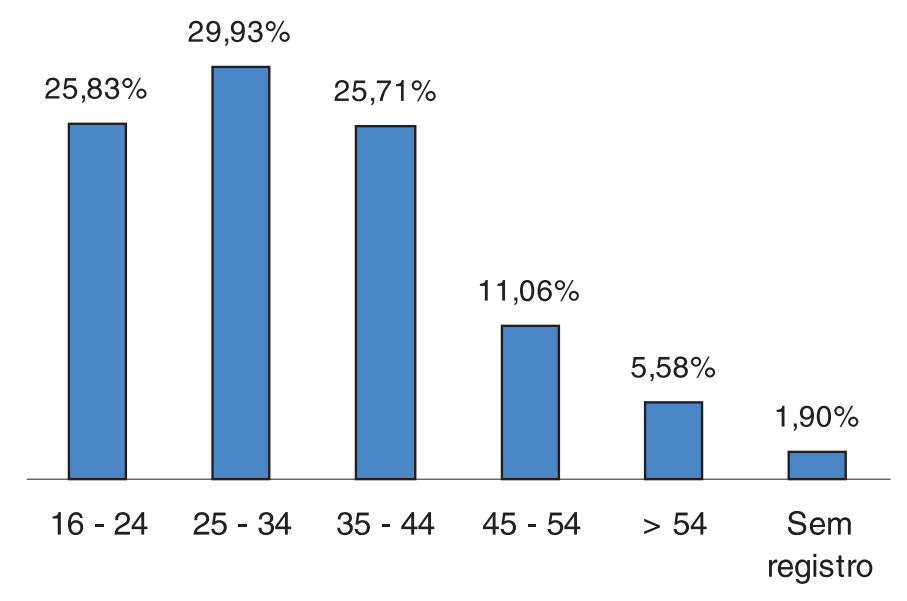

c) Faixa etária (anos)

Figura 1 Perfil dos acidentados rurais. Resultado geral obfido em dez agências do INSS - SP, ano 2000.

Dentre as tarefas executadas, o segundo maior índice de ocorrência de acidentes $(16,1 \%)$ acontece com outras tarefas diversas (serviços gerais, roçada, montagem de estufa, acoplamento/desacoplamento de implementos, secagem de grãos, moagem de milho, revisão de embalagem, pintura, limpeza de córrego, operação de forno e muitas outras). Considerado isoladamente, o percentual de ocorrências seria muito baixo, mas como não se enquadram nas principais operações agrícolas, foram assim agrupadas. Isso demonstra que os acidentes podem acontecer em quaisquer circunstâncias de trabalho e expressa a necessidade de que as medidas de segurança devem ser estudadas em todos os setores da atividade rural. As tarefas de manutenção de máquinas/equipamentos (com $8,2 \%$ ) e as tarefas de atividade florestal $(7,8 \%)$, seguem-se às tarefas diversas, na porcentagem de acidentes. 
Quadro 3 Tarefa executada. Resultado obtido em cada uma das agências INSS - SP amostradas, ano 2000.

\begin{tabular}{|c|c|c|c|c|c|c|c|c|c|c|}
\hline \multirow{2}{*}{$\begin{array}{c}\text { Item } \\
\text { verificado }\end{array}$} & \multicolumn{10}{|c|}{ Agências INSS - SP } \\
\hline & ARAQ & ASSIS & BRAG & ITAPT & ITAPV & JABOT & MARIL & ORLAN & OURIN & VOTUP \\
\hline & & & & & & $\%$ & & & & \\
\hline Manutenção & 8,2 & 8,8 & 11,8 & 12,5 & 4,5 & 7,9 & 4,8 & 4,9 & 8,3 & 12,1 \\
\hline Preparo do solo & - & 1,5 & - & - & 1,5 & - & - & - & 1,6 & - \\
\hline Plantio/semeadura & 4,9 & 5,9 & -- & - & 3,0 & 7,3 & - & 6,1 & 5,7 & 6,1 \\
\hline Tratos culturais & 6,6 & - & 7,8 & - & - & 2,6 & 7,1 & 3,7 & 10,4 & 3,0 \\
\hline Pulverização & 1,1 & - & - & - & 1,5 & 0,7 & - & 1,2 & 1,0 & - \\
\hline Colheita & 51,6 & 51,5 & 3,9 & 25,0 & 1,5 & 61,6 & 11,9 & 59,8 & 46,6 & 21,2 \\
\hline Transp. de carga & 6,6 & 2,9 & 7,8 & 10,0 & 9,0 & 3,3 & 7,1 & 2,4 & 3,6 & 6,1 \\
\hline Trato com animais & 1,1 & 4,4 & 5,9 & 10,0 & 4,5 & 0,7 & 23,8 & 4,9 & 4,1 & 15,2 \\
\hline Atividade florestal & 0,6 & - & 3,9 & 26,3 & 52,2 & - & 2,4 & 2,4 & - & 6,1 \\
\hline Deslocamento & 3,3 & 7,4 & 7,8 & 1,2 & 10,4 & 4,0 & 11,9 & 1,2 & 5,7 & 3,0 \\
\hline Outras & 15,9 & 17,6 & 51,0 & 15,0 & 11,9 & 11,9 & 31,0 & 13,4 & 13,0 & 27,3 \\
\hline
\end{tabular}

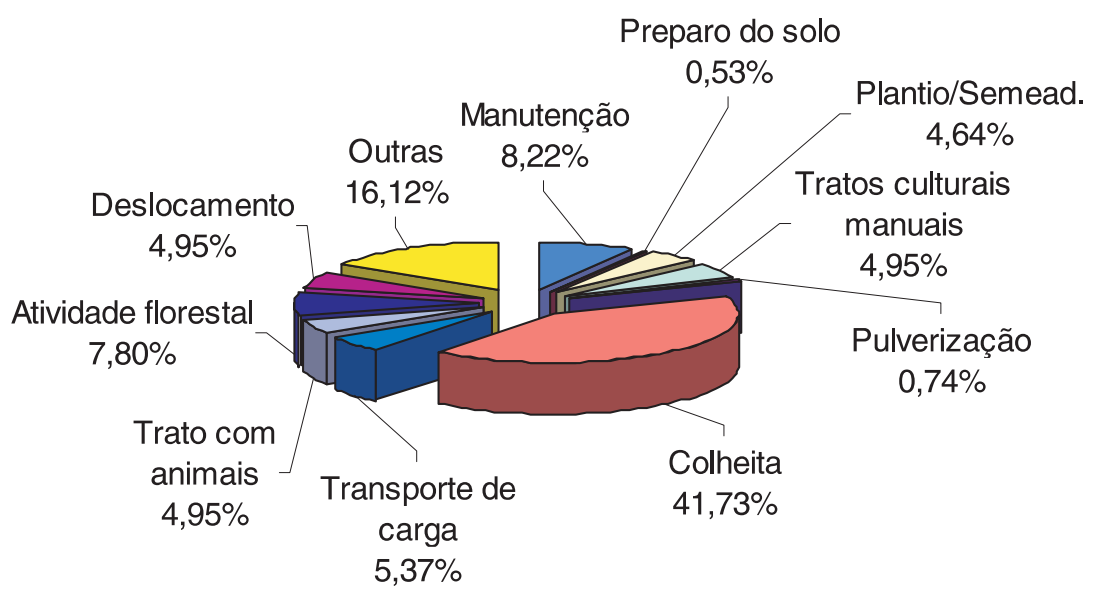

Figura 2 Tarefa executada. Resultado geral obtido em dez agências do INSS - SP, ano 2000. 
Da figura 2 pode-se inferir, também que, as ocorrências relacionadas à mecanização agrícola (manutenção, preparo de solo, tratos culturais, plantio/semeadura, pulverização e transporte de carga) atingem 24,45\%.

Cabe, destacar, observando-se o quadro 3 , que assim como a colheita na metade das agências tem a maior ocorrência de acidentes, as regiões de ltapetininga e ltapeva sobressaem com expressivos índices de acidentes na atividade florestal $(26,3 \%$ e $52,2 \%$, respectivamente), enquanto que, nas regiões de Bragança Paulista, Marília e Votuporanga os acidentes ocorrem em serviços diversos, com $51,0 \%, 31,0 \%$ e $27,3 \%$, respectivamente. Considerando-se as culturas de maior importância econômica de cada região, observou-se que nem sempre são estas cul- turas as principais fontes dos acidentes registrados nas agências. É o caso das regiões de ltapetininga e ltapeva, cuja economia é baseada nas culturas da batata, citros, hortaliças e feijão, mas que conforme se viu, a principal fonte de acidentes é a atividade florestal.

No quadro 4 e figura 3 os acidentes registrados são apresentados segundo a natureza da causa que os originaram. Verificase em geral que, os acidentes relacionados às ferramentas manuais, principalmente as decorrentes da atividade canavieira, apresentam o maior índice de ocorrência (34,2 \%) com relação à natureza da causa, seguido de naturezas diversas $(31,8 \%)$ e natureza mecânica (14,1%).

Quadro 4 Natureza da causa. Resultado obtido em cada uma das agências INSS - SP amostradas, ano 2000.

\begin{tabular}{|c|c|c|c|c|c|c|c|c|c|c|}
\hline \multirow{2}{*}{$\begin{array}{c}\text { Item } \\
\text { verificado }\end{array}$} & \multicolumn{10}{|c|}{ Agências INSS - SP } \\
\hline & ARAQ & ASSIS & BRAG & ITAPT & ITAPV & JABOT & MARIL & ORLAN & OURIN & VOTUP \\
\hline & & & & & & $\%$ & & & & \\
\hline Mecânica & 12,6 & 11,8 & 29,4 & 25,0 & 31,3 & 8,6 & 14,3 & 4,9 & 8,3 & 24,2 \\
\hline Ferram. Manuais & 49,5 & 44,1 & 11,8 & 16,3 & 3,0 & 43,0 & 9,5 & 39,0 & 42,0 & 6,1 \\
\hline Eletricidade & - & - & 2,0 & - & 1,5 & - & - & - & - & - \\
\hline Agrotóxicos & - & - & 2,0 & - & - & - & - & - & - & - \\
\hline Anim. peçonhentos & - & - & - & - & 4,5 & - & - & 1,2 & 0,5 & - \\
\hline Acid. de trajeto & 1,1 & 4,4 & 5,9 & - & 11,9 & 2,6 & 7,1 & 1,2 & 3,1 & 3,0 \\
\hline Árvore/madeira & 5,5 & - & 5,9 & 20,0 & 29,9 & 21,9 & 9,5 & 1,2 & 9,8 & 12,1 \\
\hline Anim. grande porte & 1,1 & 4,4 & 2,0 & 6,3 & 4,5 & - & 28,6 & 4,9 & 2,1 & 15,2 \\
\hline Outras & 30,2 & 35,0 & 41,1 & 32,5 & 13,4 & 23,8 & 31,0 & 47,6 & 34,2 & 39,4 \\
\hline
\end{tabular}

Com relação ao agente da lesão (ver quadro 5 e figura 4), de acordo com a classificação aqui adotada, o maior índice de acidentes tem como forma de ocorrência os choques (batidas) contra objetos/partes móveis $(43,8 \%)$, seguido de movimento brusco/falso $(15,5 \%)$ e excesso de esforço $(12,9 \%)$. O choque contra objetos ou partes mecânicas, responsável pelos $43,8 \%$ dos acidentes inclui, por exemplo, acidentes do tipo "podão ou facão atingindo uma parte do corpo", "tá- buas ou toras rolando e batendo na perna", "espinho espetado no dedo", "alavanca escapando e atingindo o tornozelo".

No quadro 6 e figura 5, são apresentadas as proporções dos acidentes com relação às partes do corpo atingidas. Fica evidente que, sendo os membros superiores e inferiores os mais expostos aos riscos durante a atividade agrícola, é natural que sejam eles os mais atingidos, chegando a totalizar $74,0 \%$ das ocorrências no cômputo geral do levantamento. 


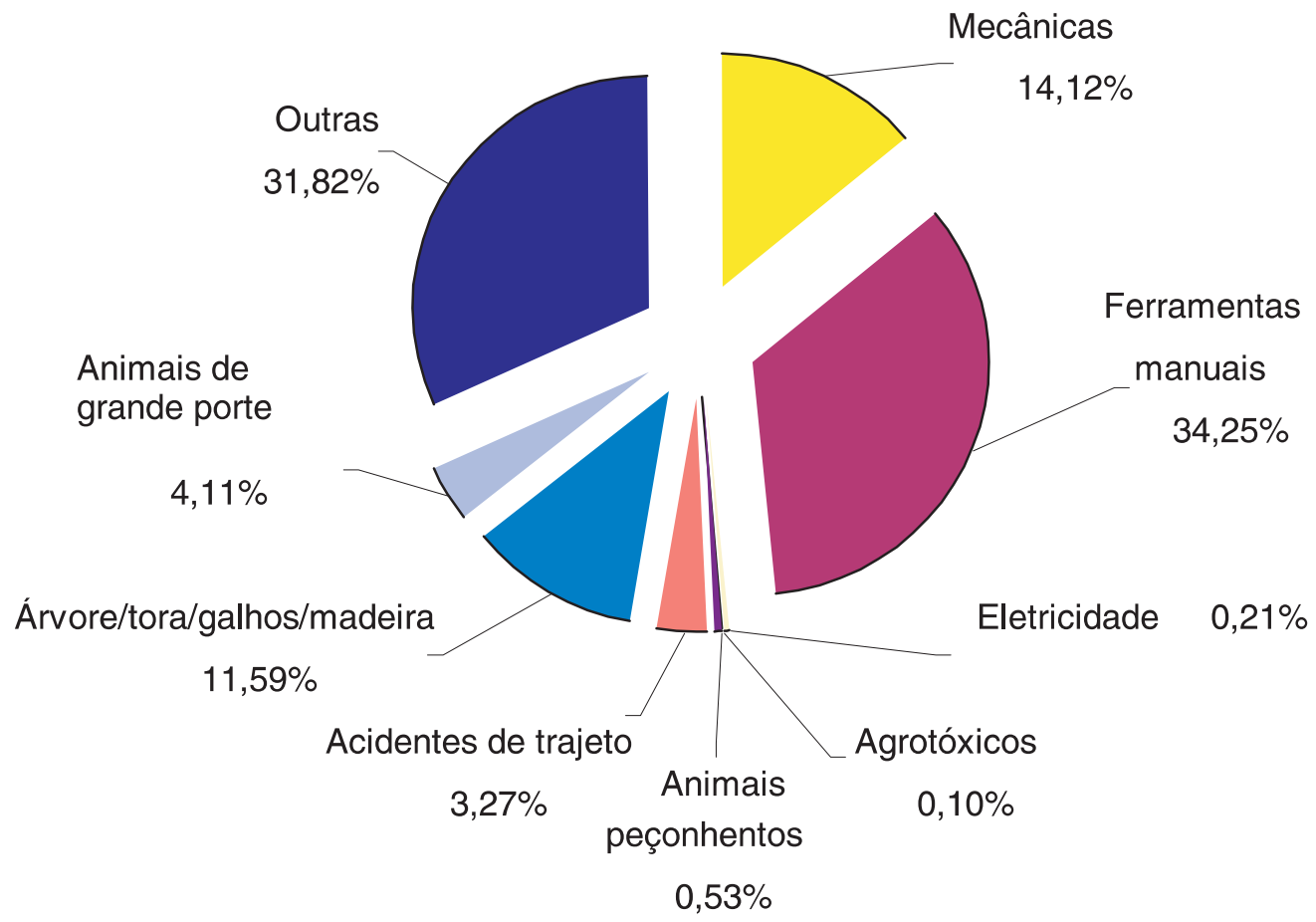

Figura 3 Natureza da causa. Resultado geral obtido em dez agências do INSS - SP, ano 2000.

Quadro 5 Agente da lesão. Resultado obtido em cada uma das agências INSS - SP amostradas, ano 2000.

\begin{tabular}{|c|c|c|c|c|c|c|c|c|c|c|}
\hline \multirow{2}{*}{$\begin{array}{c}\text { Item } \\
\text { verificado }\end{array}$} & \multicolumn{10}{|c|}{ Agências INSS - SP } \\
\hline & ARAQ & ASSIS & BRAG & ITAPT & ITAPV & JABOT & MARIL & ORLAN & OURIN & VOTUP \\
\hline & & & & & & $\%$ & & & & \\
\hline Queda de objetos & 3,3 & 2,9 & 7,8 & 33,7 & 31,3 & 2,0 & 11,9 & 6,1 & 5,2 & 3,0 \\
\hline $\begin{array}{l}\text { Queda de pessoas a } \\
\text { altura }\end{array}$ & 7,1 & 8,8 & 9,8 & 15,0 & 10,4 & 4,6 & 9,5 & 33,6 & 4,7 & 33,3 \\
\hline $\begin{array}{l}\text { Choque contra } \\
\text { objetos }\end{array}$ & 37,9 & 33,8 & 52,9 & 16,2 & 22,4 & 65,6 & 33,3 & 37,8 & 58,0 & 39,4 \\
\hline Movimento brusco & 11,5 & 13,2 & 11,8 & 18,7 & 16,4 & 11,9 & 16,7 & 31,7 & 17,6 & - \\
\hline Excesso de esforço & 34,1 & 29,4 & 5,9 & 1,3 & - & 7,9 & 4,8 & 11,0 & 66,7 & - \\
\hline Contato c/eletricid. & - & - & 2,0 & - & 11,5 & - & - & - & - & - \\
\hline Contato c/fogo & - & - & - & - & - & - & - & - & 1,0 & - \\
\hline $\begin{array}{l}\text { Exposição a produtos } \\
\text { químicos }\end{array}$ & - & - & 2,0 & 1,3 & - & - & - & - & - & 3,0 \\
\hline $\begin{array}{l}\text { Picada/mordida/ } \\
\text { pisada de animais }\end{array}$ & 1,1 & 1,5 & 3,9 & - & 4,5 & 0,7 & 9,5 & 11,2 & 2,1 & 3,0 \\
\hline Outras & 4,9 & 10,3 & 3,9 & 13,8 & 13,8 & 7,3 & 14,3 & 8,5 & 4,7 & 18,2 \\
\hline
\end{tabular}




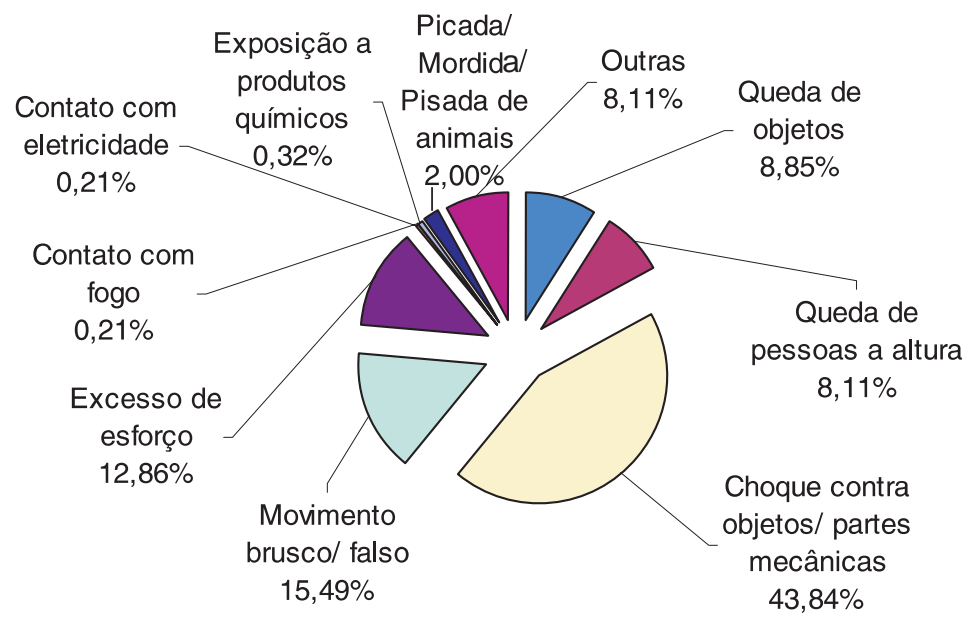

Figura 4 Agente da lesão. Resultado geral obtido em dez agências do INSS - SP, ano 2000.

Quadro 6 Partes do corpo atingidas. Resultado obtido em cada uma das agências INSS - SP amostradas, ano 2000.

\begin{tabular}{|c|c|c|c|c|c|c|c|c|c|c|}
\hline \multirow{2}{*}{$\begin{array}{c}\text { Item } \\
\text { verificado }\end{array}$} & \multicolumn{10}{|c|}{ Agências INSS - SP } \\
\hline & ARAQ & ASSIS & BRAG & ITAPT & ITAPV & JABOT & MARIL & ORLAN & OURIN & VOTUP \\
\hline & & & & & & $\%$ & & 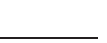 & & \\
\hline Cabeça & 8,8 & - & 23,5 & 5,0 & 6,0 & 30,5 & 7,1 & 9,8 & 13,0 & 24,2 \\
\hline Tronco & 12,1 & 8,8 & 9,8 & 3,8 & 7,5 & 6,6 & 7,1 & 13,4 & 9,8 & 6,1 \\
\hline Membro superior & 53,8 & 54,4 & 37,3 & 50,0 & 43,3 & 34,4 & 42,9 & 30,5 & 40,9 & 39,4 \\
\hline Membro inferior & 24,2 & 30,9 & 21,6 & 35,0 & 38,8 & 27,8 & 33,3 & 42,6 & 33,2 & 21,2 \\
\hline Órgãos internos & - & - & - & - & - & - & - & - & 0,5 & 3,0 \\
\hline Outra & 1,1 & 5,9 & 7,8 & 6,2 & 4,5 & 0,7 & 9,5 & 3,7 & 2,6 & 6,1 \\
\hline
\end{tabular}

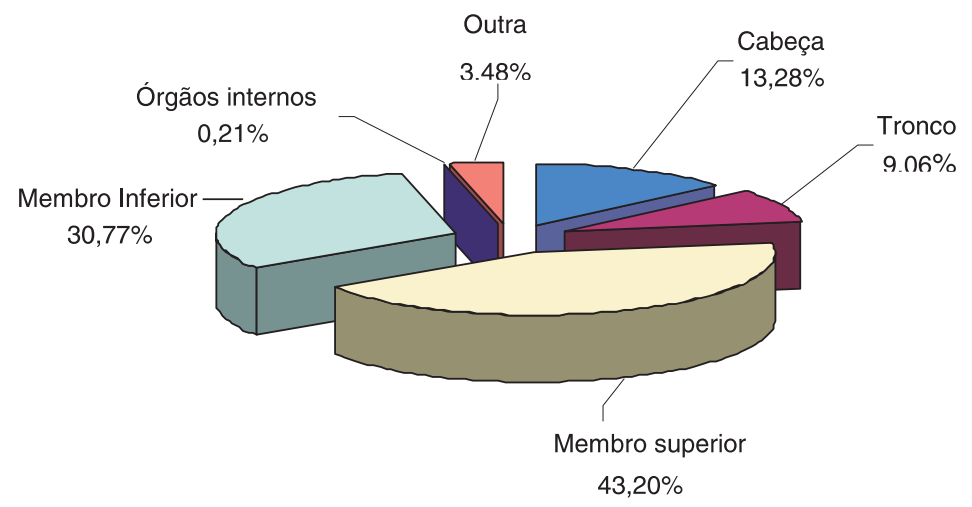

Figura 5 Partes do corpo atingidas. Resultado geral obtido em dez agências do INSS - SP, ano 2000. 
Já o tipo de lesão mais freqüente (ver quadro 7 e figura 6) nos acidentes registrados no INSS refere-se a ferimentos graves/leves ou contusões/torções, com $68,9 \%$, fraturas $(14,6 \%)$ e, a dores $(12,8 \%)$ estas, causadas geralmente por excesso de esforço ou esforço repetitivo, em jornadas excessivas típicas do trabalho manual como a colheita de cana e de laranja.

Quadro 7 Tipos de lesões. Resultado obtido em cada uma das agências INSS - SP amostradas, ano 2000.

\begin{tabular}{|c|c|c|c|c|c|c|c|c|c|c|}
\hline \multirow{2}{*}{$\begin{array}{c}\text { Item } \\
\text { verificado }\end{array}$} & \multicolumn{10}{|c|}{ Agências INSS - SP } \\
\hline & ARAQ & ASSIS & BRAG & ITAPT & ITAPV & JABOT & MARIL & ORLAN & OURIN & VOTUP \\
\hline & & & & & & $\%$ & & 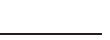 & & \\
\hline Ferim/contusão & 53,8 & 45,6 & 86,3 & 51,2 & 46,3 & 84,8 & 47,6 & 73,2 & 90,7 & 78,8 \\
\hline Fratura & 8,8 & 19,1 & 7,8 & 46,2 & 41,7 & 4,6 & 40,5 & 12,2 & 1,0 & 15,2 \\
\hline Queimadura & - & 2,9 & 2,0 & 1,3 & 1,5 & 2,0 & 2,4 & 1,2 & 1,0 & - \\
\hline Perda de membro & - & - & - & 1,3 & 4,5 & - & 4,8 & - & 0,5 & 3,0 \\
\hline Dores & 36,8 & 32,4 & 3,9 & - & - & 6,6 & 2,4 & 12,2 & 4,7 & - \\
\hline Intoxicação & - & - & - & - & - & - & - & - & - & 3,0 \\
\hline Fatal & - & - & - & - & 3,0 & - & 2,4 & - & - & - \\
\hline Outros & 0,6 & - & - & & 3,0 & 2,0 & - & 1,2 & 2,1 & - \\
\hline
\end{tabular}

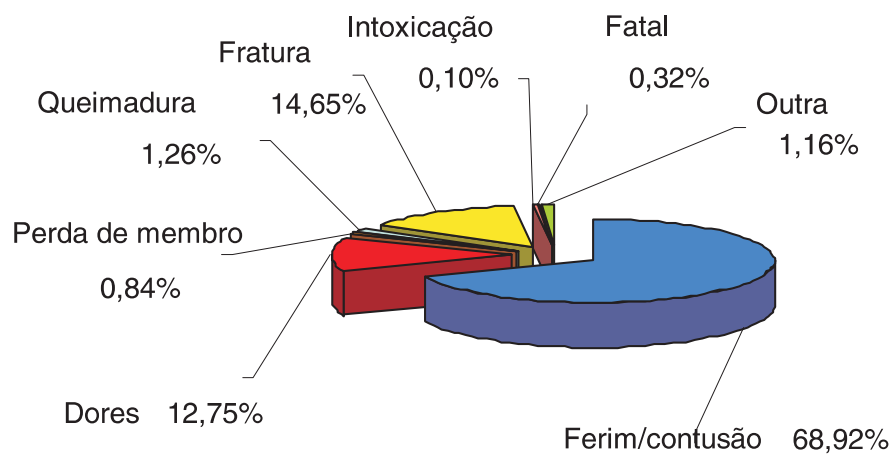

Figura 6 Tipos de lesões. Resultado geral obtido em dez agências do INSS - SP, ano 2000.

Na avaliação das conseqüências dos acidentes, cujos resultados são apresentados no quadro 8 e figura 7 , observou-se que mesmo não gerando internação das vítimas em $89,4 \%$ dos casos, os acidentes tiveram como conseqüência o afastamento do acidentado de sua atividade de trabalho. Os afastamentos com até 15 dias foram responsáveis por $59,8 \%$ das ocorrências, sendo a maior incidência os afastamentos com 8 a 15 dias (39,5\%). 
Quadro 8 Conseqüência dos acidentes. Resultado obtido em cada uma das agências INSS - SP amostradas, ano 2000.

\begin{tabular}{|c|c|c|c|c|c|c|c|c|c|c|}
\hline \multirow{2}{*}{$\begin{array}{c}\text { Item } \\
\text { verificado }\end{array}$} & \multicolumn{10}{|c|}{ Agências INSS - SP } \\
\hline & ARAQ & ASSIS & BRAG & ITAPT & ITAPV & JABOT & MARIL & ORLAN & OURIN & VOTUP \\
\hline & & & & & & $\%$ & & & & \\
\hline \multicolumn{11}{|c|}{ a) Quanto a dias de afastamento } \\
\hline - Sem afastamento & - & 23,5 & 11,8 & 1,2 & 3,0 & 1,3 & 9,5 & 24,4 & 3,6 & 3,0 \\
\hline - Até 7 dias & 16,5 & 17,6 & 31,4 & 2,5 & 14,9 & 19,9 & 11,9 & 7,3 & 36,8 & 33,3 \\
\hline - De 8 a 15 dias & 32,4 & 27,9 & 41,2 & 18,7 & 19,4 & 58,3 & 16,7 & 35,4 & 58,0 & 36,4 \\
\hline - De 16 a 30 dias & 26,4 & 22,1 & 7,8 & 41,3 & 22,4 & 4,0 & 47,6 & 8,5 & 0,5 & 15,2 \\
\hline - De 31 a 60 dias & 14,8 & 2,9 & 5,9 & 20,0 & 20,9 & 7,9 & 11,9 & 15,9 & 0,5 & 3,0 \\
\hline - De 61 a 90 dias & 6,6 & 1,5 & - & 6,3 & 7,5 & 1,3 & - & 6,1 & 0,5 & 3,0 \\
\hline$>$ de 90 dias & 2,7 & - & - & 3,7 & 10,4 & 6,6 & 2,4 & 1,2 & - & 6,1 \\
\hline - Sem registro* & 0,5 & 4,4 & 1,9 & 6,3 & 1,5 & 0,7 & - & 1,2 & - & - \\
\hline \multicolumn{11}{|c|}{ b) Quanto à internação } \\
\hline - Sem internação & 95,62 & 91,2 & 88,2 & 86,3 & 55,2 & 94,7 & 73,8 & 89,0 & 97,4 & 87,9 \\
\hline - Com internação & 4,4 & 8,8 & 11,8 & 13,7 & 40,2 & 4,0 & 26,2 & 9,8 & 2,6 & 12,1 \\
\hline - Sem registro* & - & - & - & - & 4,5 & 1,3 & - & 1,2 & - & - \\
\hline
\end{tabular}

* Informação ausente no formulário compilado.

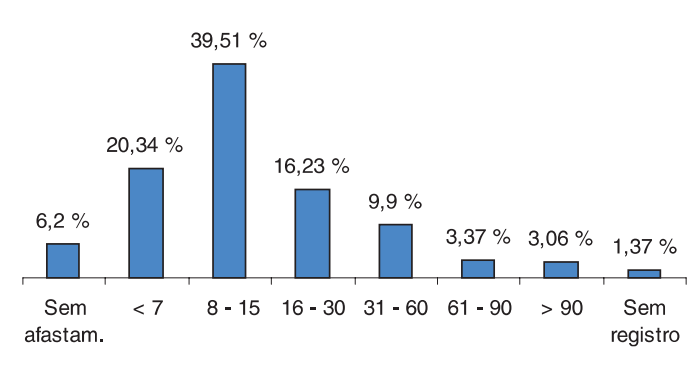

a) Afastamento (dias)

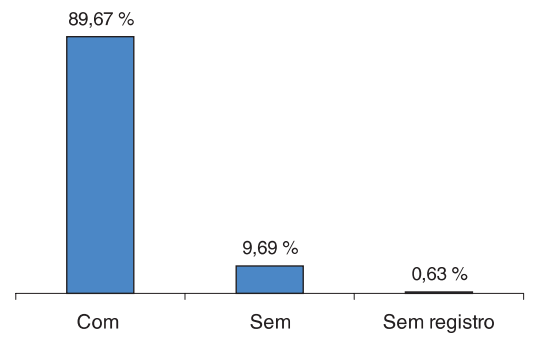

b) Internação

Figura 7 Conseqüência dos acidentes. Resultado geral obtido em dez agências do INSS - SP, ano 2000.

\section{Relatos de acidentes registrados}

\section{Na agência do INSS de Araraquara}

Dentre os acidentes registrados em Araraquara, a maioria, relacionada à cultura da cana-de-açúcar e laranja, destacamos os seguintes:
- ao efetuar serviço de solda em implemento, um estilhaço de ferro atingiu seu olho direito; - ao fazer manutenção no tanque do pulverizador sua mão ficou presa entre as correias; - ao manusear o facão durante o corte de cana passou a sentir dores no membro superior direito (diversos relatos)

- estava subindo no ônibus estacionado no talhão de cana, quando veio a bater a cabeça no mesmo 
- ao guardar a bomba de herbicida no canhão, esta se soltou atingindo a cabeça da vítima

- durante o plantio de cana, a vítima prendeu o pé no estrado do caminhão, causando torção

- ao fazer reparo em trator, o capô caiu sobre sua cabeça, ferindo-o

- ao desmontar máquina de fazer silagem, uma peça caiv em seu pé direito

- o trator estava estacionado no talhão de cana, quando desengatou vindo a tombar e atingindo o joelho esquerdo da vítima

- estava cortando tora de madeira com motosserra quando a mesma escapou de seu controle provocando corte profundo em sua perna

- ao desengatar a carreta de cana do caminhão, este se deslocou prensando sua mão direita

- caminhava pela rua de cana quando pisou em um buraco torcendo sua perna

- durante o corte de cana, o facão atingiu sua mão/perna (diversos relatos)

- ao montar o cardan foi prensado pelo mesmo causando fratura na mão direita

- estava empilhando caixa de laranja quando passou a sentir forte dor lombar

- ao colher laranja escorregou da escada, batendo a cabeça/as costas/os braços (diversos relatos)

- ao engatar os sacolões de laranja no guincho, o trator andou, a vítima enroscou o pé na alça do sacolão e o pneu do trator passou em cima de seu pé direito

- ao efetuar colheita de laranja, sentiu dores na coluna devido ao peso da sacola de laranja

- durante colheita de laranja, bateu o cotovelo num espinho, cujo ferimento veio a infeccionar

- estava trocando a roda do caminhão, quando esta caiu sobre sua mão esquerda, causando fratura

- ao engatar o cabo no trator para puxar o caminhão, o trator andou vindo a ferir sua mão esquerda

\section{Na agência do INSS de Assis}

Também aqui a maioria dos acidentes está relacionada à cultura de cana-de-açúcar.
Alguns exemplos são assim relatados:

- ao cortar cana, o facão desviou e atingiu seu joelho causando ferimento

- ao limpar a caixa de rejeito de açúcar, queimou a mão esquerda com a calda

- trabalhava descarregando o caminhão de cana no plantio, quando sentiu dores na região lombar (vários registros)

- trabalhava no corte de cana para muda, quando pisou em um toco de cana, sofrendo entorse no joelho direito

- estava cortando cana, quando o facão feriu sua mão (vários registros)

- trabalhava no corte de cana para muda quando sentiu fortes dores no antebraço (vários registros);

\section{Na agência do INSS de Bragança Paulista}

Ao contrário de outras regiões, praticamente a metade dos acidentes registrados no INSS de Bragança Paulista, como "rurais", não se refere à atividade tipicamente rural. Muitos se relacionam a serviços de construção civil, de oficina, serviços gerais e atividades corriqueiras como colocar lenha no forno, dar partida em caminhão e, inclusive confraternizando em churrasco, mas por terem ocorrido em zona rural foram assim enquadradas no INSS.

Dentre os relacionados às atividades rurais, destacam-se os seguintes relatos:

- ao cortar eucalipto, a árvore caiu sobre seu ombro esquerdo, fraturando-o;

- ao utilizar o trator em serviço de silagem, perdeu o controle do veículo, que tombou, causando-lhe fratura no braço direito;

- durante coleta de sêmen de touro, este investiv em sua direção, derrubando-o e machucando braços e pernas;

- carregando saco de produto químico, sofreu torção na coluna;

- por descuido, sua mão direita foi parar na máquina de picar cana;

- levantou a carreta (carregada) do trator, causando dor na coluna;

- limpando o secador de café, bateu sua cabeça, ferindo-se;

- ao ligar o moinho para fazer a moagem do milho, a vítima escorregou, batendo a mão na proteção do moinho e ferindo o dedo polegar;

- estava colhendo abóbora, quando derru- 
bou uma abóbora numa poça d' água com veneno, que espirrou em seu olho direito; - ao utilizar a motosserra para cortar lenha, um pedaço pulou ferindo sua boca.

\section{Na agência do INSS de Itapetininga}

Constata-se que a maioria dos acidentes registrados em ltapetininga está relacionada às atividades de colheita de laranja e cana $(25,0 \%)$ e à atividade florestal $(26,3 \%)$. Alguns exemplos são assim relatados:

- estava em cima da escada quando o galho onde a mesma estava apoiada quebrou, derrubando-o ao chão.

- ao cortar cana, o facão escapou e atingiu na boca ou na perna (vários registros)

- escorregou da escada machucando a mão ou o joelho ou a coluna ou a bacia (várias citações)

- ao colher laranjas espetov espinho no dedo

- ao cortar eucalipto a árvore caiu sobre sua perna (vários registros)

- durante o corte de árvore, o galho ou tora, o machado escapou atingindo ou o pé direito, o cotovelo ou sua perna (vários registros)

- ao cortar o tronco de uma árvore, uma das partes rolou atingindo sua perna esquerda - pisou em buraco ao carregar madeira

- cortando árvore, a motosserra escapou atingindo sua perna esquerda.

\section{Na agência do INSS de Itapeva}

Apesar da produção agrícola de maior importância econômica da região ser proveniente da cultura de hortaliças (inclusive cebola e alho), feiião e milho, a maioria (52,2\%) dos acidentes registrados no INSS de ltapeva estão relacionados à atividade florestal (corte de árvores). Os seguintes exemplos de acidentes nessa atividade são relatados:

- o trabalhador ao serrar uma árvore teve o olho perfurado por um cavaco de madeira - ao manusear a tora de madeira, esta rolou, esmagando seu dedo polegar direito

- durante a derrubada da árvore, a mesma caiu sobre seu pé direito

- ao cortar galho de árvore, o facão escapou e atingiv o dedo polegar esquerdo

- durante desgalhe de eucalipto, a motosserra escapou de sua mão atingindo seu joelho

- ao serrar tábuas, uma delas escapou atingindo sua perna direita.

- estava ao lado de uma pilha de toras quando uma rolou e caiu sobre suas costas

- feriu o dedo ao cortar madeira na serra circular

- ao cortar árvore, um galho atingiu sua cabeça, ocasionando fratura e coma profundo

- escorregou na madeira, caindo sobre seu braço esquerdo

- ao puxar tora com o machado, este escapou de sua mão, dando mau jeito nas costas

- ao cortar árvore de pinus, cortou a perna direita com a motosserra

- uma das toras de madeira rolou e atingiv a perna direita do acidentado

Nas demais atividades, tem-se como exemplo, os seguintes casos de acidentes:

- picada de cobra na mão esquerda, ao roçar o mato manualmente

- escorregou do cavalo e fraturou o pé

- transportava feijão em uma carreta puxada por trator quando este tombou em um barranco, prensando e matando o operador

- picada de cobra, ao manusear saco de batatas no campo

- desmontando a embreagem do trator, prendev o dedo na base do rolamento

- queda da carroceria de caminhão

- prendeu a roupa no eixo cardan que acionava um pulverizador, que rompeu dando volta com a vítima, ferindo-a na cabeça e bacia

- prensou o braço entre a semeadora e o pára-lama do trator, durante a subida do hidráulico

- enroscou a mão na correia do triturador de milho

- quando roçava o mato, foi picado por uma cobra, vindo a falecer.

\section{Na agência do INSS de Jaboticabal}

Constatou-se que a maioria dos acidentes registrados em Jaboticabal está relacionada à cultura da cana-de-açúcar, dentre as quais destacamos as seguintes:

- estava cortando cana quando o facão atingiu sua mão/braço/joelho ou perna - ao cortar cana, a ponta da mesma atingiu 
seu olho causando irritação ou ferimento

- quando plantava cana, a carreta tombou prensando sua perna

- estava cortando cana quando escorregou e torceu sua perna direita

- ao cortar cana infeccionou o calo da mão direita

- ao descer da carreta torceu o tornozelo esquerdo

- jogando lenha na caldeira o mesmo veio a prensar seu dedo na mão esquerda

- em serviço de limpeza da moenda, o mesmo foi atingido por água quente no pé esquerdo

- ao cortar cana, sentiu fortes dores no braço/ombro/coluna

- ao ajustar a articulação da carreta de cana a mesma atingiu sua cabeça

- ao abrir a tampa de alimentação da turbina de açúcar, recebeu vapor quente de melaço, sofrendo queimadura no rosto e braço esquerdo

Nas demais atividades, destacam-se as seguintes:

- estava cortando cano com a lixadeira quando saiu uma fagulha que atingiu seu olho esquerdo

- ao colocar a cordoalha no pino do hidráulico do trator, o pino escapou e prensou sua mão

- ao fazer ponta em uma estaca de madeira com uma serra circular ligada, um pedaço de madeira enroscou no disco, vindo a atingir sua testa

- ao descer do trator, desequilibrou-se e bateu as costas no pneu do trator

- o trator perdeu o freio, o funcionário correu para segurar, vindo a cair e o pneu passou por cima de sua perna, fraturando-a - estava colhendo laranja, caiu da escada torcendo o pé direito

- ao alavancar um implemento, a alavanca escapou vindo a atingir seu tornozelo esquerdo

- ao chegar perto do canhão de pulverização para desligar o batedor, o bico do mesmo girou devido a problema mecânico atingindo seu rosto

\section{Na agência do INSS de Marília}

Constata-se que a maioria dos acidentes registrados em Marília está relacionada à atividade com animais $(23,8 \%)$ e outras $(31,0 \%)$, como serviços gerais na propriedade. Alguns exemplos, são assim relatados nas atividades com animais:

- ao tocar as vacas para a sala de ordenha a trabalhadora foi pisada por uma das vacas;

- manejando o gado, um dos animais caiu sobre sua perna direita;

- ao retirar uma vaca de dentro do caminhão, esta investiu sobre o trabalhador, prensando sua mão na carroceria.

- ao levar as vacas para ordenhar, uma delas prensou o trabalhador contra uma das barras de ferro da ordenhadeira;

- ao efetuar castração em bovinos, levou um coice de um dos bois, atingindo o braço direito:

- quando fazia a higienização no ubre da vaca, esta bruscamente movimentou a pata atingindo o dedo da funcionária;

- quando tocava vacas, o cavalo em que estava tropeçou e a vítima caiu, sofrendo fratura na clavícula.

Em outras atividades alguns dos relatos são: - quando o funcionário cortava grama em terreno acidentado, o mesmo pisou em falso, caindo e sofrendo lesão nos ligamentos do joelho esquerdo;

- ao cortar o fio de arame da cerca, uma ponta atingiu seu braço na altura do punho

- quando cortava bambu com machado, o bambu atingiu seu nariz

- quando engatava carreta no trator, a mesma escapou e o cabeçalho atingiv o dedo polegar da mão direita

- quando cortava prancha de madeira com motosserra, escorregou e a mesma atingiu seu pé esquerdo

- o funcionário estava carregando terra em caminhão para levar ao viveiro de mudas, quando houve desmoronamento de terra, soterrando-o e matando-o.

Cabe destacar também, algumas ocorrências na atividade de colheita:

- em serviço de sangria de seringueira (coIheita de látex) ao se deslocar de uma árvore para outra, tropeçou em um toco, caindo e machucando o braço esquerdo

- estava colhendo café sobre uma escada, quando esta caiu, quebrando seu braço direito.

- efetuava corte de cana quando começou a sentir dores no braço direito (esforço repetitivo). 
- ao tentar desenroscar a correria da máquina de colher amendoim, a mesma puxou seus dois dedos, prensando-os entre a corrente.

\section{Na agência do INSS de Orlândia}

Em Orlândia, a maioria dos acidentes $(59,8 \%)$ está relacionada ao corte de cana onde os seguintes exemplos de acidentes são relatados:

- estava cortando cana quando o podão atingiu seu dedo polegar esquerdo (vários registros)

- estava cortando cana quando torceu seu punho direito

- estava cortando cana, quando o podão atingiv o dedo do pé direito (vários registros)

- ao cortar cana, uma folha da mesma atingiu seu olho

- estava cortando cana, quando o podão escapou e cortou seu joelho esquerdo ou direito

- ao abaixar-se para cortar cana, sentiu fortes dores na região lombar (vários registros)

- estava cortando cana quando sentiu fortes dores no punho direito

- ao se abaixar durante o corte de cana, bateu o olho esquerdo no toco de uma ponteira de cana

\section{Na agência do INSS de Ourinhos}

Constatou-se que a maioria dos acidentes registrados em Ourinhos (cerca de $60 \%$ ) está relacionada à cultura da cana-de-açúcar. Alguns exemplos de acidentes são relatados a seguir:

- a funcionária ao limpar a enxada sofreu corte na mão direita

- capinando cana, uma folha atingiu seu olho esquerdo (diversos relatos)

- encontrava-se sobre a carroceria de um veículo na descarga de cana, quando pisou em falso torcendo o joelho esquerdo

- estava combatendo as pragas da cana, escorregou e caiu ferindo o braço direito

- no plantio de cana, ao auxiliar o tratorista a descarregar a carreta, teve seu pé direito prensado pelo hidráulico do trator causando ferimento
- prestava serviço no plantio de cana, quando começou a sentir dores no braço direito - ao retornar do trabalho, o ônibus que transportava os trabalhadores colidiu com um caminhão e a vítima fraturou a perna

- ao apertar a carga de cana, o cabo da catraca escapou e bateu fortemente em seu tórax.

- ao trocar o disco de base da colhedora de cana, a chave escapou e sua mão esquerda bateu na base do cortador, ferindo-a

- no corte de cana, feriu seu ouvido esquerdo com uma ponta de cana

- estava cortando cana ao se abaixar, sua coluna travou e não se levantou mais

- auxiliava no serviço de queima de cana quando teve sua mão e antebraço direito atingidos pelo fogo

Em outras atividades, destacam-se os seguintes relatos:

- estava roçando à beira da cerca de pastos quando feriv o olho com capim colonião

- estava colocando lâmina na roçadora, quando feriv o braço esquerdo com a mesma

- o empregado caiu da carroça, batendo as costelas na lateral da mesma

- ao auxiliar na troca de uma peça do trator, este caiu sobre seu pé direito

- estava aplicando veneno quando, ao descer do tanque do trator, escorregou torcendo o tornozelo

- ao colocar a botina foi picado por uma aranha que estava dentro dela

- trabalhava com a plantadora e ao tentar tirar uma pedra que enroscou na corrente, seu dedo indicador direito ficou prensado, ferindo-o

- o funcionário sofreu queimadura no rosto devido ao manuseio incorreto de álcool por outro funcionário que estava colhendo café quando seu dedo indicador ficou preso na escada

- estava derriçando café e feriu o olho direito com um galho de café

\section{Na agência do INSS de Votuporanga}

Os acidentes registrados no INSS de Votuporanga estavam relacionados a atividades rurais diversas. Entre eles, destacamse os seguintes:

- ao carregar a motosserra, escorregou vin- 
do a cair e machucar sua mão esquerda

- em colheita de laranja, machucou o braço com espinho de laranjeira

- estava fazendo tratamento de semente de milho com Furadan, quando sentiu mal

- andava a cavalo laçando gado quando caiu do animal e este sobre sua perna causando fratura

- estava apertando as facas da forrageira quando sua mão esquerda escapou da chave provocando um corte no contato com uma das facas

- foi colocar o pino da lâmina niveladora no trator agrícola, quando a mesma caiu sobre seu pé direito

- perdeu os dedos de uma mão quando alimentava o triturador de cana

- quando cortava cana teve seu olho atingido pela ponta da mesma (diversos casos)

\section{Considerações gerais}

A experiência de amostragem nos arquivos do INSS mostrou que as informações ali cadastradas não estão facilmente acessíveis, o que em parte, depende do nível de organização da agência e em parte, devido à CAT estar misturada a diversos outros processos (benefícios por invalidez, aposentadoria, licença-maternidade, etc.). A princípio, pensou-se, na alternativa de buscar a informação sobre acidentes junto aos Sindicatos dos Trabalhadores Rurais, pois conforme previsto na legislação, a eles deve ser destinada uma cópia da CAT. Buscou-se, então, pela Internet e na Federação dos Trabalhadores da Agricultura do Estado de São Paulo FETAESP uma relação e endereço dos Sindicatos Rurais para posterior consulta. $\mathrm{Ne}-$ nhum endereço foi localizado e nem se recebeu qualquer retorno da FETAESP. Consultando, então, o Sindicato dos Trabalhadores Rurais em Jundiaí, foi-nos passada a informação de que há muitos anos não recebem cópia do documento.

Enviou-se, também, consulta a diversas Subdelegacias Regionais do Trabalho sobre o assunto, recebendo-se respostas variadas:

a) a Subdelegacia de Marília confirmou o recebimento da CAT e acrescentou que são inspecionados os locais de acidentes de todos os casos fatais e graves;

b) a Subdelegacia de Sorocaba informou que a "entrega de uma das vias é de responsabilidade da empresa onde ocorrev o acidente e analisada pelos auditores da área de Segurança e Saúde do Trabalhador";

c) a Subdelegacia de Araçatuba disse que o "recebimento desse documento varia com a localidade, sendo comum a sua entrega nos plantões de atendimento ao público do setor de Segurança e Saúde do Trabalhador";

d) a Subdelegacia de Barretos informou que "não é comum o recebimento da CAT";

e) a Subdelegacia de Franca disse que "não está recebendo nenhuma das vias da $C A T$, procedimento que ocorreu durante um tempo e depois foi interrompido";

f) a Subdelegacia de Piracicaba informou que "normalmente a CAT não lhes é enviada, nem pelo INSS nem pela empresa, apesar da obrigação legal de sua apresentação; e que somente durante a fiscalização de denúncia de acidente de trabalho rural é requerida a CAT".

g) A Subdelegacia de Araraquara informou que "não tem sido comum o envio da via CAT-DRT pelas empresas; poucas o fazem". Assim, "em fiscalizações para apuração de acidentes de trabalho solicitam diretamente a CAT para a empresa." Por isso, fizeram "solicitação aos funcionários do INSS responsáveis pela recepção, que passaram a reservar uma via a mais, quando da apresentação, as quais passaram a recolher periodicamente."

h) A Subdelegacia de Bauru informou que "vem recebendo as vias das CATs da seguinte forma: - através de parceria com a Agência do INSS de Bauru; - através de encaminhamento de empresas as quais procuram atender a legislação em vigor; - através de solicitação da Auditoria Fiscal do Ministério do Trabalho e Emprego, em diligência a empresas atendendo o assunto pertinente".

Acredita-se que também ajudaria bastante se os acidentes na área rural fossem organizados/arquivados à parte dos demais. Isso não seria difícil, pois no formulário de preenchimento da CAT, há um campo para identificação da área (1 - urbana; 2 - rural). Na ausência desse nível de organização, a 
destinação das CATs aos Sindicatos Rurais e às Subdelegacias Regionais do Trabalho, conforme prevê a legislação facilitaria a consulta, a análise dos dados e a manutenção de estatísticas, pois todo o processo poderia, talvez, ser realizado pelos próprios funcionários do órgão. Seria evitado, portanto, que todo interessado em estatísticas de acidentes do trabalho rural, tivesse de efetuar o seu próprio levantamento. A realização e a manutenção das estatísticas, se assumida por um dos órgãos citados e disponibilizada na Internet daria uma grande contribuição para o estudo dos acidentes no meio rural.

São possíveis de serem verificados: a faixa etária do acidentado, a tarefa em execução na hora do acidente, a parte do corpo atingida e o tipo de lesão ocorrida. A forma de ocorrência ou tipificação do acidente em classes, também é possível, dependendo dos critérios adotados para a organização da informação.

Espera-se que os exemplos e características dos acidentes aqui relatados promovam a discussão sobre acidentes rurais, principalmente em cursos de treinamento, cujo conteúdo programático deveria contemplar aspectos gerais de segurança, mas, também enfoques específicos direcionados à atividade dos treinandos, tais como, trabalho com ferramentas manuais, trato com animais, cuidados no deslocamento no local do trabalho, manutenção de máquinas, etc.

\section{Conclusões}

1. As cópias das CATs rural não são enviadas sistematicamente aos Sindicatos Rurais e às Subdelegacias Regionais do trabalho, como é previsto na legislação. Esta prática, se bem organizada, seria importante para a manutenção de um banco de informações sobre acidentes.

2. O cadastro de acidentes do trabalho (CAT) existente no INSS embora forneça uma descrição muito sucinta do acidente rural, permite extrair informações genéricas importantes para o estudo dos mesmos e detectar pontos críticos das atividades agrícolas com respeito à segurança.

3. Os acidentes rurais levantados junto ao INSS caracterizavam-se como ocorridos predominantemente na colheita manual de produtos agrícolas (cana, laranja, café) seguidos daqueles provenientes da atividade mecanizada. Ainda que de natureza leve, na maioria das vezes, tais acidentes causaram afastamento do trabalho de até 15 dias, em mais da metade dos casos registrados, enquanto que nos municípios com exploração florestal o afastamento de acidentados supera os 15 e 30 dias em proporções elevadas.

4. Pelos relatos presentes nas CATs confirma-se que, muitos acidentes poderiam ser evitados se as máquinas e equipamentos envolvidos no acidente fossem dotados de dispositivos de segurança, se equipamentos de proteção individual fossem utilizados corretamente e se princípios de segurança fossem observados durante a execução das tarefas. 


\section{Referências bibliográficas}

ARGENTINA. Siniestralidad. Acessado em 10/05/2001. Superintendencia de riesgos Del trabajo. Disponível na Internet: http://www.stt.gov.ar.

BRASIL - MPAS - Ministério da Previdência e Assistência Social. Indicadores dos acidentes do trabalho. Acessado em 24/03/ 2003. Online: http://www.mpas.gov.br.

BRASIL - MPAS - Ministério da Previdência e Assistência Social. Anuário Estatístico da Previdência Social. Acessado em 24/03/ 2003. Online: http://www.mpas.gov.br.

FUNDACENTRO - FUNDACÃO DUPRAT FIGUEIREDO DE SEGURANÇA E MEDICINA DO TRABALHO. Relatório do Projeto 04/01/17-Cadastro de Acidentes do Trabalho Rural, 57 p. (cópia xerográfica)

ROBIN, P. \& YAMASHITA. R. Y. Estudo e proposta de método alternativo para o corte da cana-de-açúcar. Revista Brasileira de Saúde Ocupacional, São Paulo, v. 16, n. 64, out-nov-dez, 1988, p. 41-50.

RODRIGUES, V. L. G. S. \& SILVA, J. G. Acidentes de trabalho e modernização da agricultura brasileira. Revista Brasileira de Saúde Ocupacional, São Paulo, v. 14, n. 56, mai, 1986, p. 28-39.

SILVA, J. R. da; SIDOU, N. B. \& FURLANI NETO, V. L. Acidentes graves no trabatho rural: III. Causas e partes do corpo atingidas. In: CONGRESSO BRASILEIRO E ENGENHARIA AGRÍCOLA, XXXIX. Anais ... (CD-ROM). Fortaleza, UFPb, julho, 4.7, 2000.

SILVA, J. R. da \& FURLANI NETO, Acidentes graves no trabalho rural: Caracterização. In: CONGRESSO BRASILEIRO DE ENGENHARIA AGRÍCOLA, XXVII. Anais ... (CD-ROM). Pelotas: UFPel, 19-21, 1999.

SHLOSSER, J. F.; PARCIANELLO, G.; DEBIASI, H. \& RAMBO, L. Caracterização dos acidentes com máquinas agrícolas no Brasil. 5p. (cópia xerox).

SHLOSSER, J, F, \& DEBIASI, H. Acidentes com tratores agrícolas: Caracterização e prevenção. Santa Maria: UFSM/CCR/Departamento de Engenharia Rural, 2001. 87 p. (Caderno didático, 8). 
ANEXO

FORMULÁRIO DE COLETA DE DADOS DA COMUNICAÇÃO DE ACIDENTES DO TRABALHO RURAL DO INSS

Projeto: DIAGNÓSTICO DAS CONDIÇÕES DE SEGURANÇA NO USO DE TRATORES AGRÍCOLAS

Proc. FAPESP 99/06.116-1

MUNICÍPIO/ESTADO:

FICHA №

\section{DADOS DO ACIDENTADO}

1.1 Sexo: ( ) Masc. ( ) Fem. 1.3 Estado Civil: ( ) Casado 1. 4 Ocupação:

1.2 Data de nascimento:
( ) Solteiro
( ) Viúvo
( ) Separado
( ) Outro

\begin{tabular}{|c|c|c|}
\hline \multicolumn{3}{|l|}{ 2. DADOS SOBRE O ACIDENTE } \\
\hline $\begin{array}{l}\text { 2.1 Tarefa executada: } \\
\text { ( ) Manutenção } \\
\text { ( ) Preparo do solo } \\
\text { ( ) Plantio/semeadura } \\
\text { ( ) Trato cultural manual }\end{array}$ & $\begin{array}{l}\text { ( ) Pulverização } \\
\text { ( ) Colheita } \\
\text { ( ) Transporte de carga } \\
\text { ( ) Trato com animais }\end{array}$ & ( ) Deslocamento \\
\hline $\begin{array}{l}\text { 2.2 Parte do corpo atingida: } \\
\text { ( ) Cabeça (olhos, boca, etc) } \\
\text { ( ) Tórax/coluna }\end{array}$ & $\begin{array}{l}\text { ( ) Membro superior } \\
\text { ( ) Membro inferior }\end{array}$ & $\begin{array}{l}\text { ( ) Órgãos internos } \\
\text { ( ) Outra: .................... }\end{array}$ \\
\hline $\begin{array}{l}2.3 \text { Tipo de lesão: } \\
\text { ( ) Ferimento leve (corte, etc) } \\
\text { ( ) Perda de membro } \\
\text { ( ) paralisia } \\
\text { ( ) Torção }\end{array}$ & $\begin{array}{l}\text { ( ) Queimadura } \\
\text { ( ) Perda de visão } \\
\text { ( ) Fratura } \\
\text { ( ) Intoxicação }\end{array}$ & 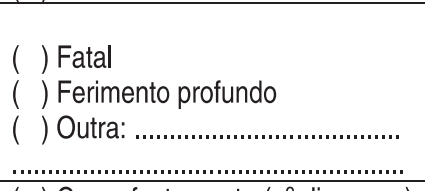 \\
\hline 2.4 Gravidade do acidente: & ( ) Sem afastamento & ( ) Com afastamento (no dias: ..... ) \\
\hline 2.5 Caso de internação: & ( ) Sim & ( ) Não \\
\hline $\begin{array}{l}\text { 3. NATUREZA DA CAUSA } \\
\text { ( ) Mecânica/máquinas (ex.: trator, in }\end{array}$ & mento, cardan, motosserr & dora, etc.) \\
\hline ( ) Ferramentas manuais (ex.: enxac & foice, facão, pá, ancinho, ma & \\
\hline ( ) Eletricidade (ex.: fio, motor, poste, & ansformador, etc.) & \\
\hline ( ) Agrotóxico (ex.: inseticida, herbicic & fungicida, outros) & \\
\hline ( ) Animais peçonhentos (ex.: cobra & ranha, escorpião, lacraia, out & \\
\hline ( ) Acidente de trajeto (informar veíc & utilizado: trator, caminhão, c & , bicicleta, outro) \\
\hline ( ) Árvore/ tora de madeira/galho & & \\
\hline ( ) Animais de grande porte & ( ) Fogo & ( ) Fertilizantes \\
\hline
\end{tabular}

RESUMO DO ACIDENTE: 